\title{
Local Participation in The Development of Klayar Beach Tourism in Pacitan Regency
}

\section{Partisipasi Lokal dalam Pembangunan Wisata Pantai Klayar di Kabupaten Pacitan}

\author{
M. Husni Tamrin*, Wildan Taufik Raharja \\ Universitas Hang Tuah, Surabaya
}

\section{ABSTRACT}

This study aims to analyze the process of local participation in the development of Klayar Beach tourism in Pacitan Regency by looking at the compatibility between the dynamics of increasing tourists and the participation of local communities in development. From this, it is known to what extent the contribution and participation of local communities in tourism development participation efforts. The implication of this research is an explanation related to the results of the analysis of the gaps in the stages of participation by the local community as managers. The research method is descriptive analytic by using triangulation as a data analysis technique. The results show that local participation runs in all stages of the development of the Klayar Beach tourist area from the beginning, tourism issues, planning, implementation and governance, to monitoring and evaluation. The lack of local participation lies in participation in terms of anticipating tourist arrivals at certain times and moments, in which case the local community as managers experience limitations in terms of capacity. To overcome this, the researcher suggests that efforts be made to increase local capacity both in terms of quality and quantity so that local participation efforts can run optimally in the development and sustainability process, and be able to overcome unexpected problems through the role of participation. This effort also refers to the opinion of several experts who state that local participation is one of the main keys in developing the tourism sector.

ISSN 2338-445X (online)

ISSN 2527-9246 (print)

Edited by:

Sulikah Asmorowati

Reviewed by:

Lely Indah Mindarti and Sri Maryuni

*Correspondence:

M. Husni Tamrin

m.husnitamrin@hangtuah.ac.id

Published: 29 September 2021

Citation:

Tamrin, M.H and Wildan Taufik Raharja (2021). Local Participation in The Development of Klayar Beach Tourism in Pacitan Regency.

JKMP(Jurnal Kebijakan dan

Manajemen Publik).9:2.

doi: 10.21070/jkmp.v9i2.1576
Keywords: Local Participation, Tourism, Klayar Beach, Pacitan Regency

\section{PENDAHULUAN}

Kabupaten Pacitan merupakan salah satu kabupaten di Provinsi Jawa Timur yang letaknya berada paling selatan dan barat provinsi, sehingga menjadikan kabupaten tersebut berbatasan langsung dengan Provinsi Jawa Tengah. Batas wilayah lain dari Kabupaten Pacitan antara lain Kabupaten Ponorogo (utara), Kabupaten Trenggalek (timur), dan Samudera Hindia (selatan). Kabupaten Pacitan terletak pada koordinat $110^{\circ} 55^{\prime}-111^{\circ} 5^{\prime}$, bujur timur (BT) dan $7^{\circ} 55^{\prime}-8^{\circ} 17^{\prime}$ lintang selatan (LS), dengan luasan wilayah $1.389,8716 \mathrm{~km} 2$ atau $138.987,16$ Ha. Secara administratif, kabupaten Pacitan terdiri dari 12 kecamatan.

Dalam mengandalkan perekonomian masyarakat lokal, Kabupaten Pacitan merupakan daerah yang mengandalkan potensinya pada sektor pariwisata khususnya daya tarik alam. Keberadaan wisata salah satunya Pantai Klayar di Kabupaten Pacitan terus dikembangjkan agar mampu menyediakan benefit positif seperti lapangan kerja, peluang usaha penjualan 
barang/jasa, pemasukan dari bagi hasil pengelolaan wisata, dan dampak lainnya. Pemerintah daerah juga memberikan apresiasi dan dorongan bagi masyarakat lokal untuk berpartisipasi dalam pembangunan wisata. Hal ini tercantum salah satunya melalui komitmen pembangunan kepala daerah di Kabupaten Pacitan yang ditamkan pada misi "meningkatkan pertumbuhan ekonomi melalui sektor agraris, sektor pariwisata dan sektor unggulan lainnya". Di samping itu, capaian terkait pariwisata juga tampak melalui adanya peningkatan jumlah kunjungan wisatawan di Kabupaten Pacitan, khususnya di wisata Pantai Klayar.

Tabel 1.1

Angka Kunjungan dan Pertumbuhan Wisatawan di Kabupaten Pacitan 2011-2015

\begin{tabular}{lccccc}
\hline & 2011 & 2012 & 2013 & 2014 & 2015 \\
\hline Pantai Teleng Ria & 224.201 & 242.796 & 121.562 & 317.419 & 427.262 \\
Pertumbuhan (\%) & - & 8,2 & $-49,9$ & 161,1 & 34,6 \\
Goa Gong & 126.580 & 138.193 & 138.036 & 214.370 & 138.036 \\
Pertumbuhan (\%) & - & 9,1 & -0.1 & 55,3 & $-35,6$ \\
Banyu Anget & 107.891 & 115.323 & 114.639 & 128.719 & 121.528 \\
Pertumbuhan (\%) & - & 6,8 & $-0,5$ & 12,2 & $-5,5$ \\
Pantai Klayar & 40.671 & 45.891 & 50.223 & 155.883 & 352.139 \\
Pertumbuhan (\%) & - & 12,8 & 9,4 & 210,3 & 125,8 \\
\hline
\end{tabular}

Sumber: Dinas Pariwisata, Pemuda, dan Olahraga Kabupaten Pacitan (2021, diolah kembali)

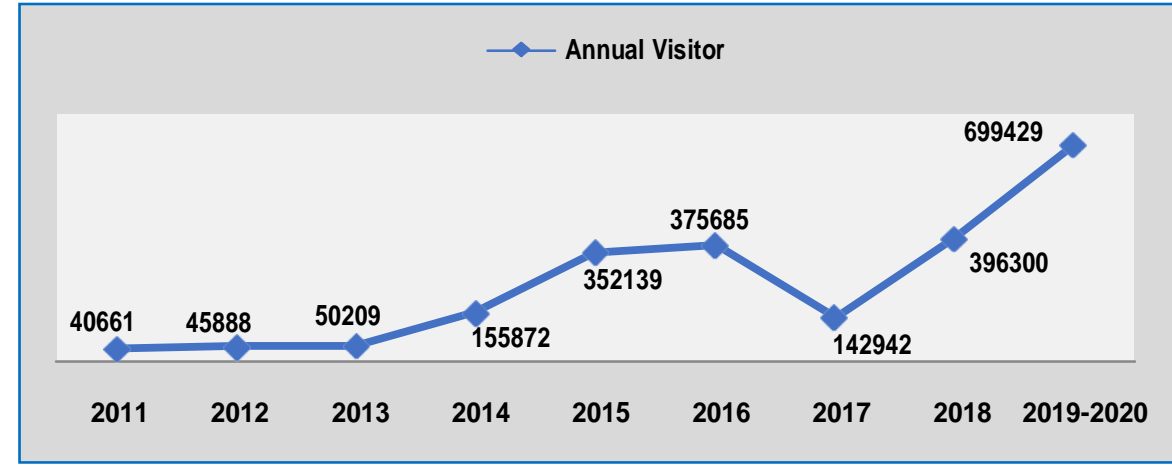

Gambar 1.1 Grafik Kunjungan Wisatawan ke Pantai Klayar

Signifikansi dan konsistensi peningkatan jumlah wisatawan di Pantai Klayar Kabupaten Pacitan mengartikan bahwa potensi wisata tersebut sangat diminati oleh wisatawan dalam atau luar negeri. Data selama 10 tahun terakhir menunjukkan adanya peningkatan dari tahun ke tahun, bahkan pada tahun tahun 2019 dan setelahnya, terjadi over target dan Pantai Klayar merupakan wisata dengan angka kunjungan tertinggi di Kabupaten Pacitan (Disparpora Kabupaten Pacitan, 2021). Dibandingkan dengan beberapa wisata lainnya di Kabupaten Pacitan yang sempat menjadi wisata yang sangat popular di tahun-tahun sebelumnya (Pantai Teleng Ria, Goa Gong, Banyu Anget, dan sebagainya), Pantai Klayar sendiri merupakan objek wisata dengan pertumbuhan jumlah wisatawan yang paling pesat meskipun berjarak sangat jauh dari kawasan pusat kabupaten (Furohmah, B., \& Setyadharma, 2018). Pertumbuhan tersebut diukur melalui angka permintaan, cost perjalanan, lama perjalanan, jarak, fasilitas, dan daya tarik ataksi alam yang dimiliki oleh Pantai Klayar. Bahkan dalam waktu 5 hari, Disparpora mampu mengantongi 237 juta dan tetap menjadi prioritas 4 besar di Jawa Timur (Pemerintah Kabupaten Pacitan, 2021).

Pantai Klayar pada dasarnya tengah dikembangkan dalam bentuk ekowisata melalui kolaborasi antar pemangku kepentingan beserta penguatan interaksinya. Kolaborasi dan penguatan interaksi tersebut bertujuan mencapai keselarasan pembangunan yang mengedepankan keberlanjutan aspek lingkungan, ekonomi, serta dampak sosial 
(Pilving, 2021). Artinya bahwa pada pembangunan kepariwisataan tersebut, orientasi bukan hanya pada peningkatan sector ekonomi saja, melainkan pada aspek sosial yang mana salah satunya dengan melihat aspek sejauh mana keberpihakan publik dalam pembangunan kepariwisataan di Pantai Klayar. Kondisi ini sejalan dengan misi utama kolaborasi pembangunan yang di dalamnya terdapat upaya mengakomodir kepentingan masyarakat lokal untuk kesejahteraan melalui peran partisipatif masyarakat (Chang, 2014), hal ini mengingat bahwa keberadaan masyarakat adalah subyek utama dalam pembangunan sebagai subjek. Kepentingan masyarakat yang disampaikan oleh (Chang, 2014) dan (Doberstein, 2016) bukan semata-mata kepentingan ekonomi, tetapi juga mengedepankan sisi-sisi keberlanjutan, pemeliharaan terhadap modal sosial yang sudah dikembangkan sedemikian rupa, serta terwujud dalam bentuk antusiasme keikutsertaan dalam proses pembangunan.

Pemerintah daerah dan masyarakat lokal berkomitmen pada dasarnya menjadikan Pantai Klayar sebagai kawasan wisata secara berkelanjutan. Di samping itu, pemerintah daerah juga memutuskan untuk menjadikan Pantai Klayar sebagai destinasi wisata unggulan berbasis komunitas (masyarakat) atau community-based tourism (CBT). Hal ini dikarenakan selain kapasitas pemerintah yang kurang optimal ketika menjadi actor tunggal dalam pelaksanaan tata kelola wisata, juga dikarenakan semakin tingginya kunjungan dari tahun ke tahun. Semakin tingginya kunjungan tersebut di satu sisi memberikan dampak ekonomi secara positif pagi masyarakat lokal, usaha dan pariwisata, tetapi di sisi lain akan muncul ancaman lainnya seperti penurunan kualitas lingkungan, sampah, perubahan tata guna lahan, ketidakpahaman wisatawan dalam berinteraksi dengan lingkungan ekowisata, dan kondisikondisi lainnya yang mengakibatkan kerusakan ekowisata pesisir (Khrisnamurti, Utami, H., \& Darmawan, 2016) (Yuliani, S., Setyaningsih, W., 2019). Berdasarkan ancaman tersebut, maka sangat dibutuhkan partisipasi masyarakat lokal di Pantai Klayar yang hari ini berperan sebagai pengelola utama sebagai upaya menanggulangi berbagai ancaman tersebut.

Penelitian ini bertujuan menganalisis proses partisipasi masyarakat lokal dalam upaya pembangunan kepariwisataan Pantai Klayar di Kabupaten Pacitan. Lebih lanjut lagi bahwa kajian ini berupaya melihat kesesuaian antara dinamika peningkatan wisatawan dengan keikutsertaan masyarakat lokal dalam pembangunan, yang kemudian dari adanya hal tersebut dapat diketahui terkait sejauh mana kontribusi dan peran serta masyarakat lokal. Implikasi penelitian ini berupa adanya penjelasan partisipasi yang diterapkan dalam tahapan pembangunan kepariwisataan di Pantai Klayar Kabuaten Pacitan yang kemudian di dalamnya terdapat hasil analisis terkait peran apa yang telah dilaksanakan oleh masyarakat lokal sebagai pengelola.

\section{Partisipasi Lokal}

Breugel menyatakan bahwa partisipasi lokal melalui kerjasama dan adanya legitimasi merupakan daya ungkit dalam mendorong keberhasilan dalam pengembangan sector wisata (Breugel, 2013). Dengan kata lain bahwa jika aspirasi dan kemampuan/kemauan lokal tidak diakomodir dalam pembangunan wisata, maka potensi wisata akan sulit meningkat, mengingat pentingnya dampak dari sikap dan respon lokal terhadap pengembangan kepariwisataan (Rastegar, 2019)(Simmons, 1994). Masyarakat dalam kerangka partisipasi lokal berperan dalam menjaga kearifan lokal, kultur, dan tradisi setempat, serta dalam pelestarian lingkungan yang dicapai melalui pelibatan tata kelola, komunikasi, dan pengambilan keputusan dalam komunitas terstruktur(Kusakabe, 2013) (Muganda, M., Sirima, A., \& Ezra, 2013). Dalam hal ini, peran partisipasi lokal erat kaitannya dengan upaya terstruktur guna mencapai tujuan bersama dan keberlanjutan kepariwisataan (Ertuna, B., \& Kirbas, 2012)(Kantsperger, M., Thees, H., \& Eckert, 2019). 


\section{METODE PENELITIAN}

Penelitian yang dilaksanakan di Kawasan Wisata Pantai Klayar di Kabupaten Pacitan ini menggunakan metode deskrriptif analitik dengan maksud melakukan deskripsi untuk kemudian dilakukan analisis dari setiap deskripsi tema pada kerangka kerangka penyajian hasil penelitian. Peneliti berupaya mengkaji dan menganalisis gambaran pelaksanaan partisipasi masyarakat pada fokus tata kelola di Pantai Klayar dengan ruang lingkup antara lain: 1) partisipasi masyarakat dalam mengawali aktifitas dan merespon isu-isu pariwisata; 3) partisipasi perencanaan; 4) partisipasi pelaksanaan tata kelola wisata; 5) partisipasi keberlanjutan tata kelola pariwisata, dan; 6) partisipasi monitoring dan evaluasi. Terdapat 2 jenis data sebagai bahan studi penelitian ini yakni data primer (hasil wawancara dengan partisipan lokal yang berkecimpung pada tata kelola wisata di Pantai Klayar) dan data sekunder (data-data statistik berkaitan dengan tata kelola wisata di Pantai Klayar, data olahan dari penelitian terdahulu, data dari media yang relevan dengan topik penelitian, dan sebagainya). Data dan hasil lapangan kemudian diolah dengan menggunakan teknik triangulasi hingga mencapai pada titik jenuh hasil kajian dan memperoleh hasil kesimpulan akhir penelitian.

\section{HASIL DAN PEMBAHASAN}

\section{Partisipasi Lokal Dalam Mengawali Aktifitas \& Respon Isu Kepariwisataan}

Pantai Klayar pada awalnya oleh masyarakat hanya dianggap sebagai kawasan pesisir biasa yang membentang di wilayah selatan Kabupaten Pacitan dan hanya menjadi kawasan beraktivitas biasa. Berdasarkan hasil wawancara dengan narasumber yang merupakan salah satu tokoh masyarakat di Desa Sendang Kecamatan Donorojo, secara historis nama "Klayar" memiliki 2 versi terkait keberadaan nama tersebut: versi pertama, menjelaskan "Klayar" diambil dari adanya fenomena kapal yang terdampar yang kemudian oleh masyarakat setempat dikenal dengan istilah "glayar" yang kemudian berangsur-angsur menjadi kata "Klayar", dan; versi kedua, "Klayar" diambil dari istilah populer yang secara terminologi banyak digunakan oleh masyarakat yakni "klayar-kluyur" yang artinya hilir mudik kesanakemari. Hingga saat ini, kedua versi terkait riwayat nama "Klayar" masih belum diketahui secara pasti mana yang benar. Namun keduanya juga menjadi semacam anggapan yang sudah dibenarkan selama bertahun-tahun dan tidak ada permasalahan terkait kedua versi nama tersebut.

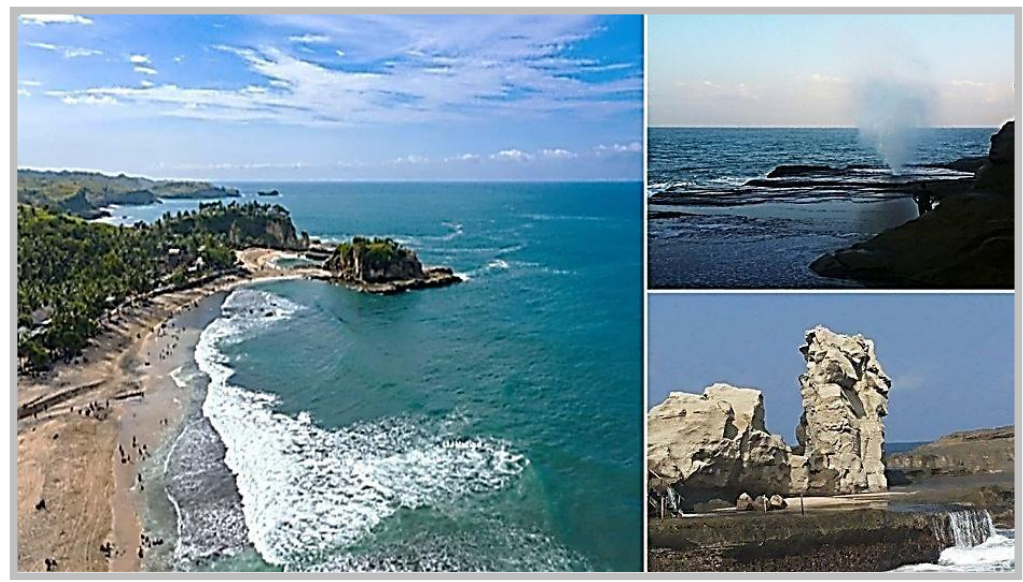

Gambar 1.2 Daya Tarik Alam Pantai Klayar

Pantai Klayar mulai dipahami sebagai kawasan wisata sejak sebelum tahun 2004 dan ketika masyarakat mulai memahami bahwa terdapat daya tarik alam yang tidak dimiliki oleh wisata pantai di tempat lainnya. Beberapa daya tarik tersebut antara lain: keindahan pantai 
dengan keberadaan tebing, air berwana hijau tosca serta dipadukan dengan pasir berwarna putih kecoklatan; seruling samudera yang merupakan spot bebatuan dengan lubang kecil, yang kemudian mampu menyemburkan air laut dan berbunyi layaknya seruling ketika air pasang (sore hari menjelang malam); watulumbung, yang merupakan batuan karang laut berbentuk patung Sphinx layaknya di Mesir, namun batu tersebut terbentuk secara alamiah yang secara visual nampak seperti singa berwajah manusia.

Respon terhadap isu kepariwisataan di Pantai Klayar dimulai sejak tahun awal 2004 ketika pemerintah daerah di Kabupaten Pacitan mengambil alih untuk melakukan pembangunan dan branding kawasan wisata. Adanya upaya tersebu oleh masuyarakta lokal disambut dengan baik dengan harapan adanya dampak positif berkenaan dengan kesejahteraan namun dengan catatan bahwa harus dilakukan upaya pelibatan masyarakat lokal dalam awal menjadikan Pantai Klayar sebagai kawasan wisata. Upaya kerjasama dan kesepakatan yang terbentuk dalam merespon isu kepariwisataan di Pantai Klayar mulai berdampak positif ketika wisatawan domestik dan mancanegara mulai datang ke Pantai Klayar. Narasumber menjelaskan bahwa pada saat itu, wisatawan tertarik untuk melihat berbagai fenomena keunikan dan daya tarik keindahan alam yang dimiliki oleh Pantai Klayar. Narasumber juga menjelaskan bahwa wisatawan domestik datang dari sekitar Kabupaten Pacitan, sedangkan wisatawan mancanegara berasal dari Amerika, Prancis, dan Australia.

Di awal terjadinya aktivitas kepariwisataan dan upaya respon atas isu pariwisata di Pantai Klayar, partisipasi masyarakat lokal diwujudkan dalam bentuk membuka usaha menjual makanan dan minuman kecil, menyediakan spot-spot untuk pengunjung yang berhenti sejenak selama perjalanan wisata ke/dari Pantai Klayar, hingga rumah makan yang dibuka untuk para wisatawan. Beberapa masyarakat lokal juga berpartisipasi sebagai pemandu wisata pada masa-masa awal dijadikannya Pantai Klayar sebagai kawasan wisata. Pemandu tersebut melayani wisatawan baik perseorangan atau grup kecil yang ingin mengetahui seputar Pantai Klayar. Umumnya, wisatawan yang menggunakan jasa pemandu lokal adalah wisatawan mancanegara yang ingin mengetahui seputar seluk beluk, daya tarik keindahan yang ditawarkan, hingga seputar kondisi sosial budaya lokal setempat.Partisipasi

\section{Perencanaan Wisata}

Peningkatan jumlah kunjungan oleh wisatawan domestik dan mancanegara pada setiap tahun yang terdokumentasikan oleh Dinas Pemuda, Olahraga, dan Pariwisata (Disporapar) Pemerintah Kabupaten Pacitan menjadikan antusiasme masyarakat lokal turut meningkat. Masyarakat memiliki ekspektasi tersendiri terkait dengan pembangunan dan pengembangan wisata Pantai Klayar di masa mendatang. Hal ini khususnya terjadi pada masyarakat lokal di Desa Sendang Kecamatan Donorojo. Pada tataran aksi, masyarakat mulai mengajukan diri dan berupaya menyalurkan aspirasi pada pihak pemerintah desa. Aspirasi tersebut berupa adanya keikutsertaan masyarakat dalam upaya pengelolaan kegiatan kepariwisataan di Pantai Klayar, yang mana Pantai Klayar sendiri merupakan salah satu asset alam yang berada di wilayah Desa Sendang Kecamatan Donorojo. Secara otomatis, masyarakat merasakan adanya kepemilikan atas wisata alam tersebut.

Pihak pemerintah desa memberikan respon positif akan adanya antusiasme masyarakat berkaitan dengan ekspektasi mengelola kawasan wisata Pantai Klayar. Respon positif diberikan dalam bentuk kesediaan untuk melakukan musyawarah terkait substansi pengelolaan, pelestarian, hingga pengembangan lanjutan untuk meningkatkan kualitas daya tarik Pantai Klayar. Sejak usulan tersebut, masyarakat mulai aktif berpartisipasi dalam kaitannya dengan penyediaan komponen kelengkapan wisata seperti peningkatan daya tarik atraksi wisata, akomodasi (penginapan), perbaikan aksesibilitas (jalur dan jalan wisata), hingga amenitas (kelengkapan pendukung seperti sarpras pendukung, kawasan usaha, rumah makan, dan sebagainya). 


\section{Partisipasi Pelaksanaan Tata Kelola Wisata}

Partisipasi lokal dalam pelaksanaan tata kelola wisata dilakukan melalui terbentuknya lembaga masyarakat lokal yang berpartisipasi sebagai pengelola kawasan wisata di Pantai Klayar. Lembaga tersebut di antaranya kelompok sadar wisata (pokdarwis), Karang Taruna, dan Badan Usaha Milik Desa (BUMDes) di Desa Sendang. Peran pengelolaan tersebut dilaksanakan dalam bentuk mengakomodir kebutuhan dan aktivitas masyarakat secara umum yang ingin berpartisipasi dalam keikutsertaan membangun wisata Pantai Klayar atau membuka usaha di wilayah Pantai Klayar.

Pembentukan lembaga masyarakat lokal pengelola Pantai Klayar terbentuk atas dasar hasil musyawarah dan rembug antar pemangku kepentingan di tingkat desa. Selain merumuskan adanya lembaga pengelola, mausyawaraah dan rembug desa juga menghasilkan adanya inisiasi dalam kaitannya dengan sarana prasarana penunjang guna mencapai kinerja kepariwisataan secara optimal di antai Klayar. Pembuatan sarana prasarana pelengkap seperti kawasan parkir pengunjung, penyediaan tempat sampah, fasilitas kamar mandi di tempat wisata, tempat ibadah, pengaturan akses mobilitas wisatawan, pelaksanaan himbauan kepada wisatawan dalam bentuk larangan tertentu (seperti larangan buang sampah sembarangan, larangan berada di lokasi bahaya, larangan melakukan ritual tertentu, larangan meletakkan sesajen, dan sebagainya), hingga mengatur kawasan usaha merupakan bentuk partisipasi selama pelaksanaan dalam pengelolaan wisata di Pantai Klayar. Partisipasi pelaksanaan tata kelola wisata ini dimaksudkan agar kawasan Pantai Klayar tetap terjaga kelestarian dan keberanjutannya sebagai kawasan wisata alam dengan kualitas keasrian dan tata kelola yang baik, sehingga konsisten menjadi objek daerah tujuan wisata (ODTW) unggulan baik di skala lokal di Kabupaten Pacitan, atau skala yang lebih luas yakni Provinsi Jawa Timur.

\section{Partisipasi Keberlanjutan dan Pengembangan Tata Kelola Pariwisata}

Partisipasi lokal dalam keberlanjutan dan pengembangan tata kelola pariwisata berkaitan dengan upaya yang dilakukan oleh para pengelola yang dalam hal ini masyarakat setempat di kawasan wisata Pantai Klayar untuk menjaga kualitas daya tarik dan daya dukung kepariwisataan di dalamnya. Keberlanjutan ini berkaitan dengan adanya aspek 4A yang telah dimiliki oleh Pantai Klayar antara lain: aspek atraksi, berupa daya tarik alam beserta panorama keindahan dan fenomena keunikan tertentu yang telah dijaga dengan baik dalam hal pastisipasi lokal untuk menjaga kebersihan kawasan wisata; aspek aksesibilitas, berupa akses jalan dan model pengaturan jalur yang telah dikelola sedemikian rupa; aspek amenitas, berupa sarana prasarana pendukung seperti kamar mandi, rest area, kawasan parkir, sarana ibadah, serta pendukung lainnya yang telah disediakan dan dikelola dengan baik, dan: anciliary atau ketersediaan oganisasi dalam pengelolaan kawasan wisata di Pantai Klayar yang dalam hal ini telah terpenuhi di awal-awal perencanaan pembangunan kepariwisataan.

Pada konteks partisipasi lokal dalam keberlanjutan dan pengembangan tata kelola pariwisata Pantai Klayar, sejatinya terdapat beberapa hal yang masih harus diperhatikan dan dibenahi. Untuk saat ini, partisipasi lokal secara mendasar telah banyak berkontribusi dalam membangun wisata Pantai Klayar. Namun yang menjadi kewaspadaan adalah kedatangan wisatawan yang dari tahun ke tahun semakin meningkat dan peneliti melihat bahwa belum ada strategi teknis dalam proses pengembangan alur kedatangan wisatawan. Peneliti melihat bahwa di satu waktu atau hari tertentu, terkadang Pantai Klayar sangat sepi pengunjung, namun di sisi lain kunjungan di Pantai Klayar sangat membludak. Adanya fenomena ini tentu saja akan menjadikan adanya ancaman dan kerugian terkait dengan daya dukung dan daya tampung kawasan wisata Pantai Klayar yang tidak seimbang. Berkaitan dengan hal ini, maka sangat dibutuhkan partisipasi lokal khususnya dalam aspek pengaturan jadwal kedatangan wisatawan di Pantai Klayar. Di samping itu, pemeliharaan fisik oleh masyarakat pengelola terkait sarana prasarana yang sudah ditetapkan sebelumnya serta upaya memelihara hubungan, interaksi, dan modal sosial antar masyarakat lokal dalam lingkup pengelola wisata juga sangat dibutuhkan berkaitan dengan keberlanjutan kualitas wisata beserta pengembangannya. 


\section{Partisipasi lokal dalam Monitoring dan Evaluasi Pembangunan Wisata}

Sejauh ini, partisipasi lokal dalam proses monitoring dan evaluasi pembangunan wisata di Pantai Klayar sudah dilakukan dalam bentuk evaluasi internal, melakukan pola sinergi dengan pemerintah daerah beserta stakeholder lainnya, serta melihat tren-tren dari pengembangan wisata di luar Pantai Klayar. Tingginya jumlah wisatawan pada dasarnya mendorong pihak pengelola untuk berpikir lebih keras agar membenahi kawasan wisata melalui upaya monitoring dan evaluasi. Beberapa monitoring dan evaluasi berisikan terkait pencapaian sasaran dan tujuan, target jumlah pengunjung, target pendapatan, tata kelola wisata, interaksi antar pengelola, interaksi dengan pemerintah daerah dan stakeholder lainnya, hingga mengevaluasi strategi yang disusun dalam mengatasi berbagai masalah kepariwisataan baik yang terduga maupun yang tidak teduga. Partisipasi lokal dalam proses monitoring dan evaluasi ini dalam rangka keikutsertaan masyarakat lokal dalam menilai sejauh mana pembangunan dan pengembangan wisata Pantai Klayar berjalan sebagaimana harapan-harapan yang sudah ditetapkan.

\section{KESIMPULAN}

Pantai Klayar yang telah dibangun mulai tahun 2004 melalui respon terhadap isu kepariwisataan dimulai oleh pemerintah daerah di Kabupaten Pacitan, yang dalam hal ini adalah Disporapar Pemerintah Kabupaten Pacitan dalam bentuk pengambil alihan untuk proses pembangunan dan branding kawasan wisata di awal tahapan. Pada tahap tersebut, partisipasi lokal masyarakat telah muncul dan memegang peranan penting seiring dengan diawalinya isu dan proses pembanguan kepariwisataan di Pantai Klayar. Pada tahap lainnya seperti perencanaan, tata kelola, dan monitoring/evaluasi, partisipasi lokal terbukti mampu mengawal secara penuh dan terbukti mampu menjadikan keunggulan pengelolaan wisata berbasis masyarakat yang secara secara garis besar memiliki kualitas partisipasi yang baik. Dari segi kekurangan, partisipasi lokal masih menemui kendala khususnya dari segi keberlanjutan dan pengembangan, yang mana dalam hal ini ditandai dengan belum optimalnya strategi teknis dalam proses pengembangan alur kedatangan wisatawan yang memicu ancaman pada daya dukung dan daya tamping wisatawan. Implikasi terkait hal tersebut berupa adanya alternatif kebutuhan pengembangan lanjutan dalam konteks peningkatan kapasitas pengelola guna mengoptimalkan upaya pengembangan dan keberlanjutan serta mampu mengatasi permasalahan yang tidak terduga melalui peran partisipasi yang dimiliki.

\section{PENDANAAN}

Publikasi artikel ini menggunakan dana dari Lembaga Penelitian dan Pengabdian Masyarakat Universitas Hang Tuah Surabaya.

\section{UCAPAN TERIMA KASIH}

Pertama-tama kami ucapkan terima kasih atas kepada civitas akademika Universitas Hang Tuah Surabaya atas dukungannya sehingga artikel kami dapat di publish di Jurnal Kebijakan dan Manajemen Publik. 


\section{REFERENCES}

Breugel, L. (2013). Community-based tourism: Local participation and perceived impacts A comparative study between two communities in Thailand. Master Thesis, Faculty of Social Sciences. Radboud University Nijmegen.

Chang, H. J. (2014). Collaborative Governance in Welfare Service Delivery: Focusing on Local Welfare System in Korea. International Review of Public Administration, 13(1), 75-90.

Doberstein, C. (2016). Designing Collaborative Governance Decision-Making in Search of a Collaborative Advantage. Public Management Review, 18(6), 819841

Ertuna, B., \& Kirbas, G. (2012). Local community involvement in rural tourism development: The case of Kastamonu, Turkey. PASOS: Revista de Turismo y Patrimonio Cultural, 10(2), 17-24.

Furohmah, B., \& Setyadharma, A. (2018). Analisis Permintaan Wisatawan Nusantara Pada objek Wisata Pantai Klayar Kabupaten Pacitan. Economics Development Analysis Journal, 7(4), 412-420.

Kantsperger, M., Thees, H., \& Eckert, C. (2019). Local Participation in Tourism Development: Roles of NonTourism Related Residents of the Alpine Destination Bad Reichenhall. Stakeholder Management in Tourism Destination (Special Issue), 11(24), 1-23.

Khrisnamurti, Utami, H., \& Darmawan, R. (2016). Dampak Pariwisata Terhadap Lingkungan Di Pulau Tidung Kepulauan Seribu. Jurnal Kajian, 21(3), 257-273.

Kusakabe, E. (2013). Advancing sustainable development at the local level: The case of machizukuri in Japanese cities. Progress in Planning, 80, 1-65.

Lai, I. K. W., \& Hitchcock, M. (2017). Local reactions to mass tourism and community tourism development in Macau. Journal of Sustainable Tourism, 25(4), 451-470

Muganda, M., Sirima, A., \& Ezra, P. M. (2013). The role of local communities in tourism development: Grassroots perspectives from Tanzania. Journal of Human Ecology, 41(1), 53-66
Pemerintah Kabupaten Pacitan. (2020, November 2). Klayar Suguhkan Sunset Unik di Penghujung Cuti Bersama. Pemerintah Kabupaten Pacitan.

Pilving, E. a. (2021). Creating shared collaborative tourism identity in a post-communist environment. Scandinavian Journal of Hospitality and Tourism, 21(3), 313-340.

Rastegar, R. (2019). Tourism development and conservation, do local resident attitudes matter? International Journal of Tourism Sciences, 19(3), 181191.

Simmons, D. . (1994). Community participation in tourism planning. Tourism Management, 15(2), 98-108.

Yanes, A., Zielinski, S., Cano, M. D., \& Kim, S. (2019). Community-Based Tourism in Developing Countries: A Framework for Policy Evaluation. Tourism, Governance \& Sustainable Development (special issue), 11(9), 1-23

Yuliani, S., Setyaningsih, W., \& W. Y. (2019). Strategi Penataan Kawasan Pantai Klayar Pacitan sebagai Destinasi Pariwisata Berkelanjutan dengan Prinsip Arsitektur Ekologis. Jurnal RUAS, 16(2), 1-12.

Conflict of Interest Statement: The authors declare that the research was conducted in the absence of any commercial or financial relationships that could be construed as a potential conflict of interest.

Copyright (c) 2021 M. Husni Tamrin and Wildan Taufik Raharja. This is an open-access article distributed under the terms of the Creative Commons Attribution License (CC BY). The use, distribution or reproduction in other forums is permitted, provided the original author(s) and the copyright owner(s) are credited and that the original publication in this journal is cited, in accordance with accepted academic practice. No use, distribution or reproduction is permitted which does not comply with these terms. 